\title{
SS-56, a novel cellular target of autoantibody responses in Sjögren syndrome and systemic lupus erythematosus
}

\author{
Odile Billaut-Mulot, ${ }^{1}$ Cécile Cocude, ${ }^{1}$ Vincent Kolesnitchenko, ${ }^{1}$ Marie-José Truong, ${ }^{1}$ \\ Edward K.L. Chan, ${ }^{2}$ Eric Hachula, ${ }^{3}$ Xavier de la Tribonnière, ${ }^{4}$ André Capron, ${ }^{1}$ \\ and George M. Bahr ${ }^{1}$
}

\begin{abstract}
${ }^{1}$ Laboratory of Molecular Immunology of Infection and Inflammation, Institut Pasteur de Lille, Lille, France ${ }^{2}$ Department of Molecular and Experimental Medicine, The Scripps Research Institute, La Jolla, California, USA ${ }^{3}$ Department of Internal Medicine, Hôpital Huriez, University of Lille, Lille, France ${ }^{4}$ ISTAC Biotechnology, Lille, France
\end{abstract}

Address correspondence to: George M. Bahr, Laboratory of Molecular Immunology of Infection and Inflammation, Institut Pasteur de Lille, 1 rue du Professeur Calmette, BP 245, 59019 Lille Cedex, France.

Phone: 33-3-20-87-72-91; Fax: 33-3-20-87-72-92; E-mail: georges.bahr@pasteur-lille.fr.

Received for correspondence February 8, 2001, and accepted in revised form July 30, 2001.

Certain autoimmune disorders, including Sjögren syndrome (SS) and systemic lupus erythematosus (SLE), are characterized by autoantibodies against the Ro/SSA and La/SSB cellular antigens. Although the implication of these autoantibodies in disease pathogenesis is still unclear, it is believed that the aberrant responses against autoantigens may extend to other proteins that are not yet well defined. In an attempt to analyze the regulated gene expression in lymphocytes by an HIV-suppressive immunomodulator, we have identified and cloned a novel gene encoding a $56-\mathrm{kDa}$ protein, named SS-56, which is structurally related to the $52-\mathrm{kDa} \mathrm{Ro} / \mathrm{SSA}$ antigen. The new protein showed primarily perinuclear cytoplasmic localization, and recombinant SS-56 was found to react in ELISA with sera from most patients with SS or SLE. Western blot analysis confirmed the autoantigenic nature of native SS-56 in extracts from HeLa cells. Interestingly, the incidence of antibodies to SS-56 was associated with visceral complications in SLE, and roughly half of the 17 SS or SLE patients with no detectable antibodies to SSA and SSB antigens presented measurable antibodies against recombinant SS-56. Thus, SS-56 represents a new member of the SS family of autoantigens and could become an additional and important diagnostic marker for SS and SLE.

J. Clin. Invest. 108:861-869 (2001). DOI:10.1172/JCI200113469.

\section{Introduction}

Autoantibodies (autoAb's) to Ro/SS-A and La/SS-B cellular antigens are commonly found in sera of patients with several autoimmune diseases (1) including neonatal lupus erythematosus (NLE), Sjögren syndrome (SS), subcutaneous lupus erythematosus, systemic lupus erythematosus (SLE), and rheumatoid arthritis (RA). These autoAb's have been demonstrated to play a critical role in the pathogenesis of tissue injury (2-6). In addition, they have been reported in sera of subjects with chronic viral infections including HIV-1 patients (7). The targets for these antibodies are known to be the 60-kDa (SSA-60), the 52-kDa (SSA-52), and the 48-kDa (SSB-48) SS antigens $(8-10)$. Whereas SSA- 60 and SSB-48 proteins are known to reside predominantly in the nucleus, a cytoplasmic accumulation of the SSA-52 antigen has been described (11). The biologic function of these cellular proteins is yet to be fully elucidated; however, a role for SSA-60 has been described in the regulation of the translational fate of ribosomal protein mRNAs and in the quality control or discard pathways for $5 \mathrm{~S}$ rRNA production $(12,13)$. The SSA-52 protein has been found to bind DNA and has been suggested to act as a transcription factor regulating gene expression $(8,14,15)$. On the other hand, the SSB protein is believed to be involved in the initiation and termination of RNA polymerase III transcription, in translational control, and in regulating viral replication (16-19). The three major SS proteins, together with several other less well-characterized antigens with reported $M_{r}$ of $80,68,65,60$, and $53 \mathrm{kDa}$, are known to be associated directly or indirectly with small cytoplasmic RNAs to form complex ribonucleoprotein (hYRNPs) particles $(20,21)$. Moreover, using yeast twohybrid cloning system, a new protein, $\mathrm{Pp} 75$, was shown to interact with the SSA-60 protein (22). In addition, Bouffard et al. identified a different protein, RoBPI, that was found to associate specifically with hY5 RNPs (23). Nevertheless, the detailed molecular structure of native hYRNPs remains largely unknown, and it is assumed that these complexes contain additional components still to be identified. Clarification of this issue may provide vital information about either the function of the hYRNPs particles, the complications associated with the presence of autoAb's, or even the pathogenesis of the immune disturbances that lead to the production of such antibodies.

We have been studying the mechanism of action of immunomodulators in regulating cellular pathways implicated in the inhibition of viral replication. More specifically, we have identified a safe synthetic muramyl peptide analogue, Murabutide (ISTAC SA, Lille, France), 
with a capacity to suppress HIV- 1 replication in antigenpresenting cells (24). Recently, this immunomodulator was also found capable of regulating $\mathrm{CD}^{+}$lymphocytes from HIV-1 patients, leading to potent suppression of viral replication in vitro (25). These effects were revealed to target the nuclear transport of viral preintegration complexes and virus transcription through the regulation, at least partly, of cellular genes necessary for different steps in the virus life cycle (24-26). To better define the HIV-suppressive activity of Murabutide, we carried out a differential display analysis on CD8-depleted PBMCs, stimulated or not with Murabutide, from one HIV-1 patient. However, among the genes that were differentially expressed by Murabutide, we have cloned the full-length cDNA of one new gene that showed no identity with published gene sequences. The corresponding amino acid (aa) sequence revealed a protein with a predicted $\mathrm{M}_{\mathrm{r}}$ of $56 \mathrm{kDa}$ and presenting strong similarity with Ro/SSA-52. This protein, named SS-56, was found to be a target of autoimmune responses in patients with SS, SLE, and HIV- 1 infection. Importantly, autoAb's to SS-56 were detected in sera from a large percentage of SS and SLE patients who were negative for both SSA and SSB antibodies. Therefore, SS-56 represents a new member of the SS family of autoantigens (autoAg's) and could have important relevance for the diagnosis of certain autoimmune disorders.

\section{Methods}

Cell cultures and reagents. HeLa, U937, Jurkat, and Molt4 cell lines were maintained in RPMI 1640 supplemented with $10 \% \mathrm{FCS}, 8 \mu \mathrm{g} / \mathrm{ml}$ Gentamicin sulfate (SheringPlough, Levalois-Perret, France), and $2 \mathrm{mM}$ glutamine (Life Technologies-Invitrogen, Cergy-Pontoise, Paris).

Cloning of SS-56 cDNA. A cDNA fragment of $152 \mathrm{bp}$ that was underexpressed in Murabutide-treated, compared with untreated, CD8-depleted PBMCs from an HIV-1infected patient was isolated from differential display gels. The 152-cDNA fragment from differential display was radiolabeled with $\alpha-\left[{ }^{32} \mathrm{P}\right] \mathrm{dCTP}$, using a Megaprime labeling kit (Amersham Pharmacia Biotech, Orsay, France), and was used to screen the $\lambda$ TriplEx leukocyte cDNA library according to the manufacturer's instructions (CLONTECH Laboratories Inc., Palo Alto, California, USA). A SMART Rapid Amplification of cDNA Ends (RACE) kit (CLONTECH) was used to synthesize the $5^{\prime}$ and $3^{\prime}$ - cDNA ends. To generate the 5 '-end, four successive and specific oligonucleotides primers were used: (a) 5'-AATGCGTTTATTTCT-CCAGTTTGGCCTATTTAA-3'; (b) 5'AACTCTGCAATCATCCTCCACAGGA-3'; (c) 5'-CTGGCTCTGCTGGATGAGCTCGCTATG-3'; and (d) 5'-TCAGCCCCATTCCTGGAT-GTA-3'. The $3^{\prime}$-end of SS-56 cDNA was amplified with the following primer: 5 '-CCTGTCTGAGGCATAGAGGCAGGCAAGCCG-3'. The full-length cDNA coding for SS-56 was then obtained by RT-PCR using two synthetic oligonucleotides that included the start codon for the $5^{\prime}$-end and the stop codon for the $3^{\prime}$-end. All PCR amplification products were cloned into PCR2.1 vector (TOPO TA Cloning; Life Technologies-Invitrogen), and nucleotide sequences were determined in both strands by using dye terminator sequencing and the $\mathrm{ABI} 377 \mathrm{DNA}$ sequencer equipped with ABI Prism Model version 2.1.1 software for data recording and analysis (Perkin-Elmer Applied Biosystems, Foster City, California, USA). Both nucleotide and deduced aa sequences were analyzed for similarity with known sequences using BLAST (27) search and ExPASy proteomics tools (ExPASy, Geneva, Switzerland). The initial differential display cDNA fragment corresponded to nucleotides 3152-3304 in the complete cDNA sequence of SS-56 submitted to GenBank (Accession No. AF360739).

Northern blot analysis. A multiple tissue Northern blot was purchased from CLONTECH and was hybridized with $\alpha$-[32P]dCTP-labeled SS-56 cDNA following the manufacturer's instructions. The same blot was then stripped and rehybridized with a $\beta$-actin probe to standardize for RNA equivalence.

Expression of His-Tagged protein and production of mouse polyclonal antibody. The SS-56 cDNA was subcloned into the PQE-80 vector (QIAGEN, Courteboeuf, France) and used to transform TOP 10F' Escherichia coli (Life TechnologiesInvitrogen). The SSA-52, SSA-60, and SSB-48 cDNAs were subcloned into the pET28 vector (Novagen, Madison, Wisconsin, USA) and used to transform XL1-blue E. coli. The purification of recombinant proteins fused to six histidine was performed by using $\mathrm{Ni}^{2+}$ affinity chromatography following the manufacturer's instructions (QIAGEN). The final elution was carried out in $8 \mathrm{M}$ urea, $0.1 \mathrm{M}$ $\mathrm{NaH}_{2} \mathrm{PO}_{4}$, and $0.01 \mathrm{M}$ Tris-Cl ( $\mathrm{pH} 4.5$ ). The purified recombinant proteins were stored aliquoted at $-70^{\circ} \mathrm{C}$. To prepare polyclonal antibody, 6-week-old female BALB/c mice (Iffa-credo, l'Arbresle, France) were immunized intraperitoneally with $50 \mu \mathrm{g}$ of recombinant SS-56 (rSS56) emulsified in CFA (Sigma-Aldrich, Saint Quentin Fallavier, France). After 30 days, mice were boosted with $50 \mu \mathrm{g}$ of the same rSS-56 emulsified in incomplete Freund's adjuvant (Sigma-Aldrich). Fifteen days later, an additional boost with the same amount of rSS- 56 but without adjuvant was given to all mice. Sera were collected 10 days after the last boost and tested for the levels of anti-SS-56 antibody. Before immunization, sera from the same mice were collected and used as negative controls.

Western blot. Total cellular extracts, prepared in lysing buffer (10 mM Tris-HCl [pH 7.5], $150 \mathrm{mM} \mathrm{NaCl}, 0.5 \%$ Nonidet P-40, $1 \mathrm{mM}$ EDTA, and $0.5 \mathrm{mM}$ PMSF), and recombinant proteins were fractionated by electrophoresis on $12 \%$ SDS/PAGE, electroblotted onto nitrocellulose membranes, and incubated for 1 hour with human (1:50 dilution) or mouse (1:100 dilution) antiserum. After washing, the membranes were probed with 1:500 dilution of horseradish peroxidase-conjugated goat anti-mouse or anti-human Ig (Sigma-Aldrich). Reactive bands were then revealed by the use of either the $4 \mathrm{CN}$ peroxidase substrate system (KPL, Gaithersburg, Maryland, USA) or the ECLreagents (Amersham Pharmacia Biotech).

Indirect immunofluorescence analysis. HeLa cells grown in chamber slides (Nalge Nunc, Rochester, New York, USA) were fixed and permeabilized with ice-cold methanol/acetone $(2: 1 \mathrm{vol} / \mathrm{vol})$ for 10 minutes at $-20^{\circ} \mathrm{C}$. After soaking 


\begin{tabular}{|c|c|c|c|}
\hline SS-56 & 1 & $\begin{array}{l}\text { MDPTALVEAIVEEVACPICMTFLREPMS IDCGHSFCHSCLSGLWEIPGESQNWGYTCPLC } \\
\mathrm{M}+\mathrm{A}++\mathrm{EEV}+\mathrm{CPIC}++\mathrm{EP}+\mathrm{SI}+\mathrm{CGHSFC}+\mathrm{C}+\mathrm{S}+\mathrm{CH}^{+} \mathrm{CP}+\mathrm{C}\end{array}$ & 60 \\
\hline SA-52 & 1 & MASAARLTMMWEEVTCPICLDPFVEPVSIECGHSFCQECISQV------GKGGGSVCPVC & 54 \\
\hline SS-56 & 61 & RAPVQPRNLRPNWQLANVVEKVRLLRLHPGMGLKGDLCERHGEKLKMFCKEDVLIMCEAC & \\
\hline & & $\mathrm{R} \quad+\mathrm{NLRPN}$ QLAN+V++++ $+\quad$ G $+\mathrm{G}+\mathrm{C} \quad \mathrm{HGE}+\mathrm{L}++\mathrm{FC}++\mathrm{D} \quad{ }^{+C} \quad \mathrm{C}$ & \\
\hline SA-52 & 55 & RQRFLLKNLRPNRQLANMVNNLKE ISQEAREGTQGERCAVHGERLHLFCEKDGKALCWVC & \\
\hline SS-56 & 21 & $\begin{array}{l}\text { SQSPEHEAHSVVPMEDVAWEYKWELHEALEHLKKEQEEAWKLEVGERKRTATWKIQVETR } \\
+\mathrm{QS}+\mathrm{H} \quad \mathrm{H}++\mathrm{VP}+\mathrm{E}+\mathrm{A} \text { EY+ +L AL } \mathrm{L}+++\mathrm{Q} \text { A KLEV + A WK VET+ }\end{array}$ & \\
\hline $\mathrm{SA}-52$ & 115 & AQSRKHRDHAMVPLEEAAQEYQEKLQVALGELRRKQELAEKLEVEIAIKRADWKKTVETQ & \\
\hline SS-56 & 81 & 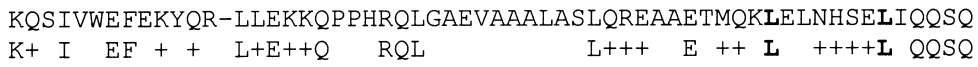 & \\
\hline SSA -52 & 175 & KSRIHAEFVQQKNFLVEEEQ---RQL------QELEKDEREQLRILGEKEAKLAQQSQ & 22 \\
\hline SS-56 & 40 & $\begin{array}{l}\text { VLWRMIAELKERSQR PVRWMLQDIQEVLNRSKSWSLQQPEPISLELKTDCRVLGLREILK } \\
+\mathrm{L}++\mathrm{I}+\mathrm{EL}+\mathrm{R}+++\mathrm{LQ}++\quad \mathrm{VL}+\mathrm{RS}+\mathrm{SW}+\mathrm{L}+++\mathrm{S} \mathrm{EL}++\mathrm{C}+\mathrm{V} \mathrm{GL}+++\mathrm{L}+\end{array}$ & \\
\hline $\mathrm{SA}-52$ & 224 & ALQELISELDRRCHSSALELLQEVI IVLERSESWNLKDLDITSPELRSVCHVPGLKKMLR & \\
\hline SS-56 & 00 & $\begin{array}{l}\text { TYAADVRLDPDTAYSRLIVSEDRKRVHYGDTNQKLPDNPERFYRYNIVLGSQCISSGRHY } \\
\begin{array}{lll}\mathrm{T} A+\text { LDPDTA } & \mathrm{LI}+\mathrm{SEDR}++\mathrm{V}+\mathrm{GDT}+\mathrm{Q}++\mathrm{P} \text { N ERF } \mathrm{Y}+\mathrm{VLG}+\mathrm{Q}+\mathrm{SG}+\mathrm{HY}\end{array}\end{array}$ & \\
\hline$S A-52$ & 284 & TCAVHITLDPDTANPWLILSEDRRQVRLGDTQQS I PGNEERFDSYPMVLGAQHFHSGKHY & \\
\hline SS-56 & 360 & 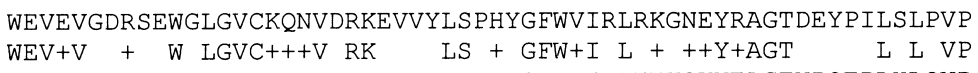 & \\
\hline SSA -52 & 344 & WEVDVTGKEAWDLGVCRDSVRRKGHFLLSSKSGFWTIWLWNKQKYEAGTYPQT PLHLQVP & 403 \\
\hline SS -56 & 420 & 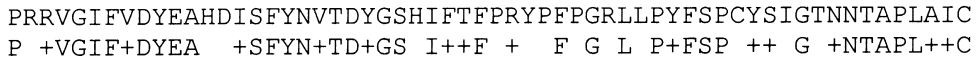 & \\
\hline SA- 52 & 404 & PCQVGIFLDYEAGMVSFYNITDHGSLIYSFSECAFTGPLRPFFSPGFNDGGKNTAPLTLC & \\
\hline SS-5 & 48 & $\begin{array}{l}\text { SLDGED } 485 \\
\text { L+ }\end{array}$ & \\
\hline$S A-5$ & & DY 475 & \\
\hline
\end{tabular}

\section{Figure 1}

Comparison of SS-56 and SSA-52 amino acid sequences. Identical amino acid sequence is indicated by a capital letter; conservative substitution in amino acid residue (+). RING finger domain is underlined, B box (Cys/His-rich) is double underlined, and Leucine Zipper region is underlined with broken lines. Nucleotide and amino acid sequences were submitted to GenBank under accession number AF360739.

in PBS containing 1\% BSA for 30 minutes, slides were incubated with the first antibody (polyclonal mouse anti-SS-56 or preimmune mouse serum) at room temperature for 45 minutes in PBS containing 0.5\% BSA. After washing with PBS, slides were stained with FITCconjugated goat anti-mouse IgG and were then incubated for 3 minutes in PBS containing $0.5 \mu \mathrm{g} / \mathrm{ml}$ propidium iodide before examination with fluorescence microscopy. Localization of SS- 56 by transient transfection. The SS- 56 cDNA was subcloned into the pEGFP vector (CLONTECH) that permits the expression of SS-56 fused with the green fluorescent protein (GFP). HeLa cells were transiently transfected by the plasmid pEGFP-SS-56 using Effectene Transfection Reagent (QIAGEN). Localization of SS-56 was analyzed by fluorescence microscopy.

Binding of SS-56 protein to DNA. rSS-56 protein produced in E. coli was used in DNA binding test as described elsewhere (15). Briefly, a saturating amount of DNA from HeLa cells was allowed to bind at room temperature to DEAE-Sephadex resin (Amersham Pharmacia Biotech) in binding buffer $(75 \mathrm{mM} \mathrm{NaCl}, 20 \mathrm{mM}$ phosphate buffer [pH 7.4]). The rSS-56 protein was then incubated for 30 minutes with DNA, and the bound protein was eluted with increasing concentrations of $\mathrm{NaCl}$ in $40 \mathrm{mM}$ phosphate buffer ( $\mathrm{pH}$ 6.7). Eluates were separated by SDSPAGE and analyzed by Western blot.
Immunoprecipitation. HeLa cells were radiolabeled overnight with $\left.{ }^{[35} \mathrm{S}\right]$ methionine, and cell lysate was prepared in lysing buffer $(10 \mathrm{mM}$ Tris- $\mathrm{HCl}[\mathrm{pH} 7.5], 150 \mathrm{mM}$ $\mathrm{NaCl}, 0.5 \%$ Nonidet P-40, $1 \mathrm{mM}$ EDTA, and $0.5 \mathrm{mM}$ PMSF). Serum from normal mice $(6 \mu \mathrm{l})$ was incubated for 1 hour on ice with $2 \times 10^{6} \mathrm{cpm}$ of radiolabeled cell extract before adding $40 \mu \mathrm{l}$ of protein $\mathrm{G}$ Sepharose beads (Amersham Pharmacia Biotech). After 1 hour of rotation at $4^{\circ} \mathrm{C}$, $25 \mu$ l of anti-SS-56 or of normal mouse serum was added to the supernatant and incubated for 1 hour on ice. Protein $\mathrm{G}$ Sepharose beads were then added in a final volume of $400 \mu$ l of lysing buffer and incubated for 1 hour at $4^{\circ} \mathrm{C}$ with continuous rotation. Sepharose beads were washed ten times with lysing buffer, and radiolabeled proteins that precipitated with the Sepharose were analyzed on $12 \%$ SDS-PAGE followed by autoradiography.

Patients. Twenty-five patients with primary SS and 22 patients with SLE were at the University Hospital Center in Lille, France. The diagnosis of each disease was based on routine clinical and laboratory parameters and, in the case of SS, on the presence of at least four items from the modified European criteria (28). The use of Ouchterlony's double immunodiffusion (ID) technique to detect antibodies against SSA and SSB antigens (3) was performed in the diagnostic laboratory of the University Hospital Center. Thirteen SS and 12 SLE patients were reported to 
be negative for SSA and SSB antibodies. Patients with SS were 19 women and six men with a mean age $( \pm S D)$ of 53 \pm 16 years, whereas SLE patients (21 women and one man) were significantly younger $(P=0.0174)$, with a mean age of $42 \pm 17$ years. A group of healthy controls ( 20 women and five men; mean age $45 \pm 14$ years) that was age- and sex-matched with both of the patient groups was included for comparative evaluation of autoAb levels. In addition, a group of 32 HIV-1-infected subjects was tested before and after treatment with potent antiretrovirals. This group was at the Infectious Diseases Department at Tourcoing Hospital Center in France and consisted of eight women and 24 men with a mean age of 37 years (range: $25-64$ years). Before starting antiretroviral therapy, the median plasma viral load was 421,326 copies $/ \mathrm{ml}$, and the mean \pm SE of CD4 counts was $150 \pm 4$ cells $/ \mu$ l. After a mean duration of 14 months of treatment with two RT inhibitors and one protease inhibitor, viral loads dropped to a median of 3,272 copies $/ \mathrm{ml}$ and CD 4 counts increased to $313 \pm 23$ cells $/ \mu$ l. The levels of antibodies in sera of HIV-1 patients were also compared with those present in sera of 32 healthy controls who were sex matched (eight women and 24 men) and age matched (mean: 38 years; range: $26-66$ years) with the patient group.

Detection of autoAb by ELISA. A standard assay was carried out as described previously (29). Briefly, microtiter plates were coated for 3 hours at $4{ }^{\circ} \mathrm{C}$ with $1 \mu \mathrm{g} / \mathrm{ml}$ each of rSSA-52, rSSA-60, rSSA-48, and rSS-56 proteins. After washes in PBS containing $0.05 \%$ Tween 20 , plates were incubated for 2 hours with different dilutions of sera $(1: 100-1: 2,700)$ from all tested subjects. Plates were washed and incubated overnight at $4{ }^{\circ} \mathrm{C}$ with peroxidase-conjugated anti-human IgG (Sigma-Aldrich). After revelation by $O$-phenylene diamine dihydrochloride substrate (Sigma-Aldrich) and $\mathrm{H}_{2} \mathrm{O}_{2}$, absorbance values were read at 492-nm wavelength using an automated microplate reader (Titertek Multiskan; Labsystems, Helsinki, Finland). Results are presented as absorbance values corresponding to the dilution (1:900 for SS and SLE patients; 1:300 for HIV patients) that gave readings in the linear phase of the antibody binding curve.

\section{Results}

Molecular characterization of SS-56 CDNA. To obtain the fulllength cDNA of SS-56, we first attempted to screen a leukocyte cDNA library with the identified cDNA fragment in differential display analysis. These attempts were not successful; therefore, we changed our strategy to a series of successive $5^{\prime}$ - and $3^{\prime}$-RACE using specific oligonucleotides. These attempts produced a substantially longer and complete cDNA of $3331 \mathrm{bp}$ containing a single open reading frame and encoding a protein of $485 \mathrm{aa}$ and a predicted $\mathrm{M}_{\mathrm{r}}$ of $56 \mathrm{kDa}$. The sequence flanking the first ATG codon is in close agreement with the eukaryotic Kozak's consensus sequence for a methionine initiation codon (30). The coding region is followed by a long $3^{\prime}$ untranslated region containing a polyadenylation signal and a short poly (A) stretch. The aa sequence analysis (Figure 1) revealed the presence of RING finger (aa
16-60)-B box (aa 98-120)-coiled coil (aa 227-248) (RBCC) structure (31). Similarity search in the GenBank database revealed $66 \%$ homology and $43 \%$ identity of the new protein with human Ro/SSA-52, a member of the RBCC family of proteins (Figure 1). Because of this similarity in sequence and in the below-described biologic profile, the new $56-\mathrm{kDa}$ protein was named SS-56. Confirmation of the size of the full-length SS-56 cDNA and analysis of the tissue expression of the new gene were carried out by Northern blot analysis. An approximately 4$\mathrm{kb}$ band was detected in all tissues, and high expression was noted in spleen and in fetal liver (Figure 2).

Immunological characterization of SS-56. The SS-56 cDNA was subcloned into the PQE80 vector, and the rSS-56, fused to 6-histidine residues, was purified on Ni-NTA resin. This protein was used to immunize mice. With the use of ELISA, the antisera obtained were found to possess high-titered and specific polyclonal anti-SS-56 antibodies. Western blot analysis using the mouse antisera showed a 58-kDa band and two smaller degradation products of the rSS-56 (Figure 3a). The same antisera also recognized a native protein, in extracts from different cell lines, as a single $63-\mathrm{kDa}$ band (Figure $3 \mathrm{~b}$ ). The higher size of the native protein, in comparison with the recombinant one, may be the result of an aberrant migration in SDS-PAGE. Moreover, preincubation of mouse antisera with an excess of rSS-56 abolished completely the detection of the native protein (Figure 3c). On the other hand, attempts to immunoprecipitate the native protein from cell extracts, using anti-SS-56 antisera bound to protein G Sepharose, was not successful. Such a difficulty in immunoprecipitating the native protein has also been reported with SSA52 and may be explained by the low expression level of the protein in question (32). Furthermore, attempts to establish a DNA-binding activity for the rSS-56 protein were repeatedly unsuccessful. This also can be attributed to the absence of a proper conformation of recombinant SS-56 produced in bacterial expression system. Using indirect immunofluorescence microscopy, we then addressed the subcellular localization of SS-56 protein in HeLa cells (Figure 4b). Strong cytoplasmic and very sharp perinuclear staining was observed when SS-56 antisera, but not normal mouse serum, was used (Figure 4a). Weak staining in the nuclei of some cells has also been noted; however, the bulk of SS-56 was found to reside in the cyto-

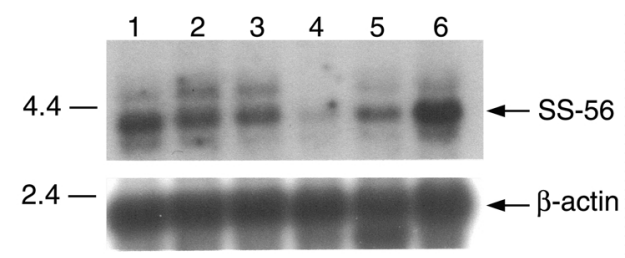

\section{Figure 2}

Northern blot analysis of SS-56 mRNA expression in normal human tissues. Multiple tissue blot (lane 1, spleen; lane 2, lymph node; lane 3 , thymus; lane 4, peripheral blood leukocyte; lane 5, bone marrow; lane 6, fetal liver) was hybridized with specific oligonucleotides for SS56 (top) or with $\beta$-actin cDNA (bottom) as described in Methods. 


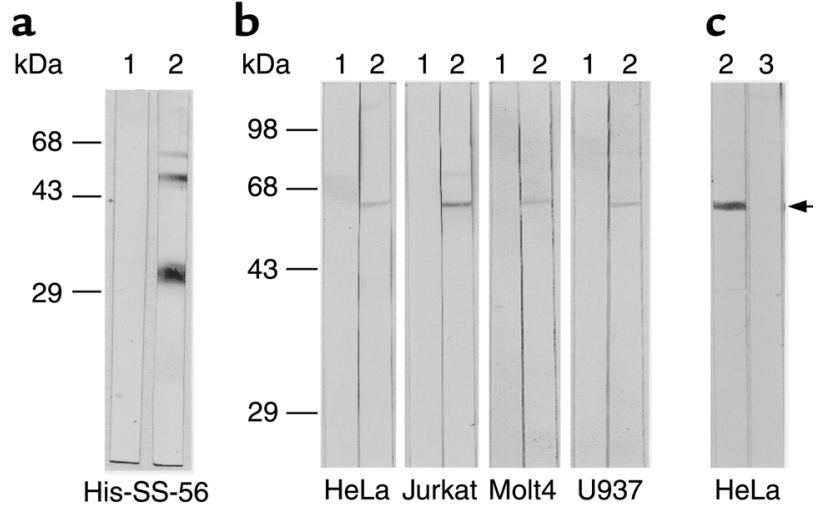

Figure 3

Western blot analysis using mouse polyclonal antiserum against SS56 . His-SS-56 recombinant protein $(1 \mu \mathrm{g} /$ lane $)$ (a) or various whole cell extracts $(130 \mu \mathrm{g} /$ lane $)$ (b and $\mathbf{c})$ were immunoblotted either with preimmune serum (lane 1), anti-SS-56 serum (lane 2), or anti-SS-56 serum absorbed with the recombinant protein (lane 3 ).

plasm. These data were also confirmed on HeLa cells that were transiently transfected with a plasmid expressing SS56 fused with GFP, and a predominant cytoplasmic staining was consistently observed (data not shown).

Detection of antibodies against SS-56 in sera from patients with SS or SLE. Because of the sequence homology between SS56 and the Ro/SSA-52 protein, we have addressed the question of whether SS-56 could serve as an autoAg in certain autoimmune disorders that are characterized by the presence of antibodies to the SSA and SSB antigens. Thus, sera from patients with SS or SLE and sera from healthy controls were analyzed, first by ELISA against SS-56 and then by ELISA against each of the three other rSSA-52, rSSA-60, and rSSB-48 proteins (Table 1). Both SS and SLE patients presented significantly higher anti-SS-56 antibodies than did healthy controls. The levels of antibodies to the SSA and SSB proteins were also higher in both groups of patients, although the difference did not attain statistical significance $(P>0.05)$ against SSB-48 and SSA-52, respectively, for the SS and the SLE patients (Table 1). Taking the cut-off value of sera positivity against a particular antigen as the mean $+2 \mathrm{SD}$ of the absorbance values from healthy controls, $64 \%$ and $68 \%$ of SS and SLE patients, respectively, were found to be positive for anti-SS-56 antibodies. In contrast, only $8 \%$ of healthy controls gave values that were higher than the mean +2 SD of the group. The percentage of positive patients to the other rSSA and rSSB proteins varied between $20 \%$ and $48 \%$, as shown in Table 1 . Moreover, when the mean +3 $\mathrm{SD}$ of the values from healthy controls was taken as the cut-off point, $32 \%$ and 54\% of SS and SLE patients, respectively, but none of the healthy controls, remained positive against SS-56. We then selected for analysis 13 SS and 12 SLE patients who were reported by the hospital (according to results from ID technique) to be negative for both SSA and SSB antibodies. The ELISA absorbance values for these 25 samples against the four recombinant proteins are shown in Figure 5. Taking as a cut-off point for each of the tested antigens the mean +2 $\mathrm{SD}$ of the absorbance values from the group of healthy controls, none of the 25 tested sera turned out to be positive by ELISA against SSB-48. In contrast, two of 13 and two of 12 patients with SS and SLE, respectively, were found to be positive against SSA- 60 . The incidence of positivity to SSA-52 was the same among SLE patients (two of 12) and slightly higher (four of 13) among SS patients. Surprisingly, eight of the 13 SS patients and eight out of the 12 SLE patients presented absorbance values against SS-56 that were above the cut-off point. Moreover, among 17 patients from both groups who presented no detectable antibodies against any of the SSA and SSB antigen, either by ELISA or by ID, nine (53\%) had measurable antibodies to SS-56. These results clearly demonstrate that anti-SS-56 antibodies are not simply crossreactive antibodies with anti-SSA-52 or anti-SSA- 60 but represent a distinct antibody population. This was further confirmed by a lack of inhibition of the binding of patients' sera to SS-56-coated wells upon the simultaneous addition of 5 $\mu \mathrm{g} / \mathrm{ml}$ of SSA-52 or of SSA-60. In contrast, a dramatic inhibition (> 80\%) could be noted when the same concentration of SS-56 protein was used. The presence of antibodies in human sera against recombinant SS-56 was also confirmed by Western blot (Figure 6a). Furthermore, sera from three of six tested patients were also found to recognize the native SS-56 protein in HeLa cell extracts (Figure 6b). Interestingly, positive sera from different patients showed different profiles of antibodies (Figure $6 \mathrm{~b}$ ) reacting with the SSA antigen alone (lane 1); with the SSA, SSB, and SS-56 proteins (lane 2); or with only SS-56 (lane 3). None of the five tested serum samples from healthy controls showed reactivity with any of the SS proteins (lane 4). The localization of the native SS-56 protein migrating as a $63-\mathrm{kDa}$ band was revealed by the use of specific mouse antiserum (lane 6) but not of normal mouse serum (lane
Table 1

Antibody levels to the different SS recombinant proteins detected in sera of healthy controls and of patients with SS or SLE

\begin{tabular}{|c|c|c|c|c|c|c|}
\hline \multirow[t]{2}{*}{$\begin{array}{l}\text { Antigen } \\
\text { tested }\end{array}$} & \multicolumn{3}{|c|}{$\begin{array}{l}\text { Healthy controls } \\
\qquad(n=25)\end{array}$} & \multirow{2}{*}{$\begin{array}{c}\text { SS patients } \\
\begin{array}{c}(n=25) \\
\% \\
\text { positive }\end{array}\end{array}$} & \multicolumn{2}{|c|}{$\begin{array}{l}\text { SLE patients } \\
\quad(n=22)\end{array}$} \\
\hline & $\begin{array}{c}\text { OD } \\
\text { values }\end{array}$ & $\begin{array}{c}\% \\
\text { positive }^{\mathrm{A}}\end{array}$ & $\begin{array}{c}\text { OD } \\
\text { values }\end{array}$ & & $\begin{array}{c}\text { OD } \\
\text { values }\end{array}$ & $\begin{array}{c}\% \\
\text { positive }\end{array}$ \\
\hline SS-56 & $\begin{array}{c}0.15^{\mathrm{B}} \\
(0.19 \pm 0.08)^{\mathrm{C}}\end{array}$ & 8 & $\begin{array}{c}0.45^{\mathrm{D}} \\
(0.59 \pm 0.53)\end{array}$ & 64 & $\begin{array}{c}0.46^{\mathrm{D}} \\
(0.49 \pm 0.26)\end{array}$ & 68 \\
\hline SSA-52 & $\begin{array}{c}0.15 \\
(0.14 \pm 0.07)\end{array}$ & 0 & $\begin{array}{c}0.26^{\mathrm{D}} \\
(1.11 \pm 1.23)\end{array}$ & 48 & $\begin{array}{c}0.20 \\
(1.16 \pm 1.30)\end{array}$ & 45 \\
\hline SSA-60 & $\begin{array}{c}0.16 \\
(0.20 \pm 0.11)\end{array}$ & 8 & $\begin{array}{c}0.29^{\mathrm{D}} \\
(0.66 \pm 0.94)\end{array}$ & 32 & $\begin{array}{c}0.36^{\mathrm{D}} \\
(1.12 \pm 1.10)\end{array}$ & 45 \\
\hline SSB-48 & $\begin{array}{c}0.07 \\
(0.08 \pm 0.04)\end{array}$ & 8 & $\begin{array}{c}0.07 \\
(0.38 \pm 0.76)\end{array}$ & 20 & $\begin{array}{c}0.10^{\mathrm{D}} \\
(0.51 \pm 0.92)\end{array}$ & 27 \\
\hline
\end{tabular}

APercentage of subjects presenting OD values above the mean +2 SD of the values observed in healthy controls. ${ }^{B}$ Median. ${ }^{C}$ Mean $\pm \mathrm{SD}$. DSignificantly different from the corresponding values of healthy controls $(P<0.05)$ by Mann Whitney's $U$ Rank Test. 

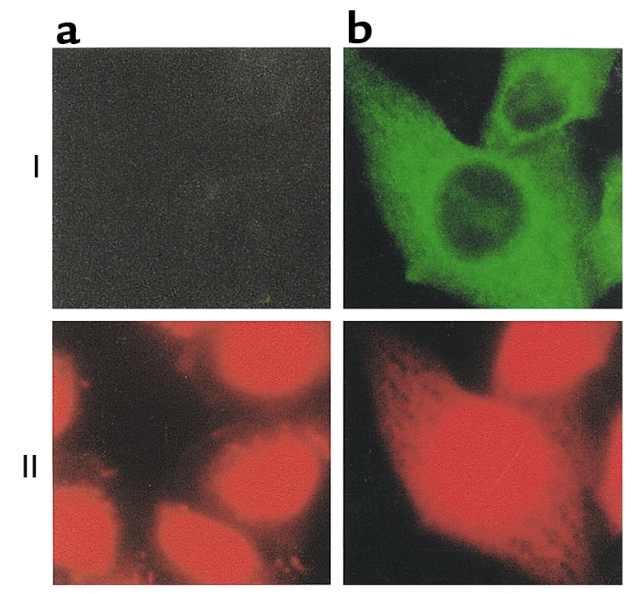

III
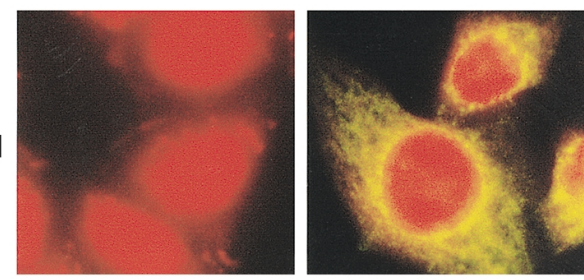

\section{Figure 4}

Cellular localization of SS-56 in HeLa cells. Cells were incubated with preimmune mouse serum (a) or with anti-SS-56 serum (b) and were stained with propidium iodide (red nuclei in II) after incubation with FITC-labeled anti-mouse Ig. Reactivity was visualized for FITC (green in I) or for FITC and propidium iodide (yellow in III) to determine the subcellular distribution of SS-56.

5). Analysis of the incidence of anti-SS-56 antibodies with various disease manifestations did not reveal any correlation among SS patients between the presence of antibodies and a defined clinical symptom or the incidence of cryoglobulinemia. However, in SLE patients, the presence of antibodies to SS-56 was frequently associated (eight of 15 patients) with a visceral manifestation (Table 2). In contrast, all seven anti-SS-56-negative patients presented only an articular form of the disease. Moreover, in a preliminary effort to gain insight into the incidence of anti-SS56 antibodies in other autoimmune diseases, we have screened few sera from patients with RA, scleroderma, or dermatopolymyositis. Results obtained by ELISA revealed that only one of seven patients with RA, one of five with scleroderma, and none of four with dermatopolymyositis were positive against SS-56 (absorbance values $>$ mean + $2 \mathrm{SD}$ of those from healthy controls). Conversely, anti-SSA-52 positivity could be detected in sera from two of four patients with dermatopolymyositis but not in sera from patients with RA or scleroderma (data not shown). These findings further dissociate the seropositivity to SS56 from that to SSA-52 and suggest the need to profile the presence of antibodies to SS-56 in large cohorts of patients with different connective tissue diseases.

Detection of autoAb against SS-56 in sera from HIV-1 patients. Because the identification of the SS-56 gene originated from cells of a subject infected with HIV-1, and given that autoAb's directed against the Ro/SSA antigen have been reported in sera of HIV-1 patients (7), we set out to determine the incidence of autoAb's to SS56 under the setting of HIV-1 infection. A cohort of 32 patients were tested before and after receiving highly active retroviral therapy (HAART), and the levels of serum anti-SS-56 antibodies were compared to those detected in sera of 32 age- and sex-matched healthy controls. Before starting treatment, patients with HIV-1 infection presented significantly higher levels of anti-SS56 antibodies $(P=0.0001)$ compared with healthy controls, and these levels were found to significantly drop $(P=0.006$ by Wilcoxon matched-pairs test) after a period of several months on HAART (Figure 7). The majority of patients (23 of 32) showed reduced absorbance values against SS-56 after antiretroviral therapy, and 11 of them presented $\geq 50 \%$ decrease in anti-SS-56 levels. Moreover, no significant difference could be found in the levels of anti-SS-56 antibodies between patients on HAART and healthy controls $(P=0.3865)$. This suggests that controlled viral replication after treatment with antiretrovirals can reduce immune activation and the incidence of antibodies in HIV-1 patients.

\section{Discussion}

RNP complexes associated with Ro/SS-A are known to be composed of small cytoplasmic YRNAs with at least the SSA- 60 and the SSB- 48 proteins (33). The interaction of SSA-52 with the Ro RNP particle, however, is less clear. Recently, pp75, a phosphoprotein that was reported to associate with the SSA-60 protein and autoAb's to Pp75 were detected in SS and lupus sera (22). In the present study, we have identified SS-56, a new protein that shares homologies with other proteins bearing RING finger domains including SSA-52, human ret finger protein (34), and staf 50 (35). The presence of RING finger, B box, and coiled-coil domains in many of these proteins has been associated with a capacity to bind DNA, to bind RNA, or to mediate protein-protein interactions (36). Although SS-56 bears all of the three domains, our attempt to demonstrate a DNA-binding activity for the recombinant protein was unsuccessful. This may reflect that there is a genuine lack of SS-56 to bind DNA or that the bacterially expressed protein is incorrectly folded after solubi-

\section{Table 2}

Association of anti-SS-56 antibodies positivity with visceral complications in patients with SLE

$\begin{array}{lccc}\text { Visceral } & \begin{array}{c}\text { Negative } \\ (n=7)\end{array} & \begin{array}{c}\text { Positive } \\ (n=15)\end{array} & P^{\mathrm{A}} \\ \text { manifestation } & 0 & 4 & >0.05 \\ \text { Glomerulonephritis } & 0 & 1 & >0.05 \\ \text { Vasculitis } & 0 & 1 & >0.05 \\ \text { Myelitis } & 0 & 1 & >0.05 \\ \text { Myelofibrosis } & 0 & 1 & >0.05 \\ \text { Pulmonary fibrosis } & 0 & 8 & 0.022 \\ \text { Total } & & & \end{array}$

AFisher's exact test. 


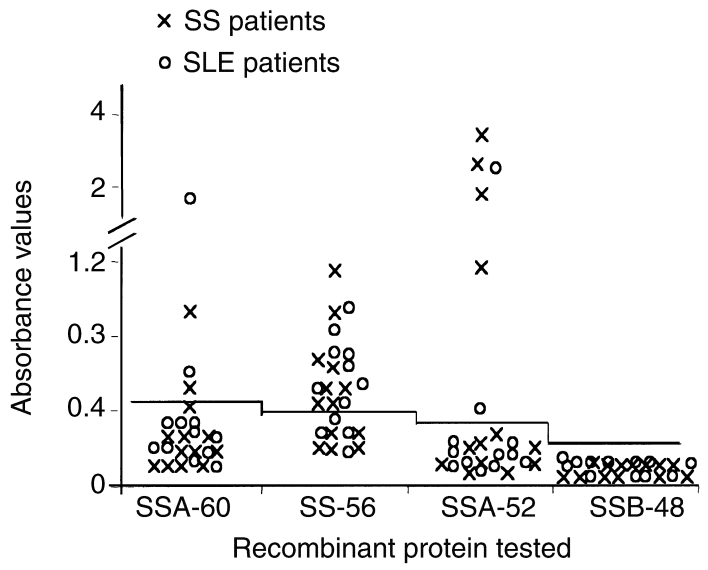

\section{Figure 5}

Levels of autoAb's against rSSA-60, rSS-56, rSSA-52, and rSSB-48 in sera from selected SS and SLE patients. Twenty-five patients (13 SS and 12 SLE), reported as negative for anti-SSA and anti-SSB antibodies by the immunodiffusion technique, were analyzed for autoAb levels to the four recombinant proteins by ELISA. Absorbance values reflect the activity at serum dilution of 1:900. Horizontal line represents the cutoff point of positivity calculated as the mean +2 SD of the values obtained from healthy controls, against each of the tested antigen.

lization in $8 \mathrm{M}$ urea, a finding previously observed with recombinant SSA-52 produced in E. coli (14). On the other hand, expression of SSA-52 in baculovirus system, which allows appropriate posttranslational modifications, may result in a protein with DNA-binding capacity $(14,15)$. This issue is currently being addressed in our laboratory. Furthermore, the question as to whether SS-56 binds to small RNAs may be examined once immunoprecipitating antibodies become available. Nevertheless, in view of the absence of RNA recognition motif in SS-56, it seems unlikely that this protein could present RNA-binding activity. Only SSA-60 and SSB-48, but not SSA-52, have been found to possess an 80-aa RNA recognition motif and to bind to hYRNAs (3).

Although the cellular localization of the SSA and SSB proteins has been controversial, there is now strong evidence that SSA- 60 and SSB- 48 are located primarily in the nucleus, whereas most of the SSA-52 is in the cytoplasm (11). Nevertheless, by using mAb anti-SSA-52, Schmitz et al. have reported either a nuclear or a nuclear and cytoplasmic localization of the protein in different cell types (37). In the present work, analysis by immunofluorescence has indicated that the new SS-56 protein is primarily located in the cytoplasm with a strong perinuclear and a weak nuclear staining. Furthermore, overexpression of SS-56 after transfection of the cDNA into HeLa cells confirmed the cytoplasmic localization of this protein. However, our results do not rule out the possibility that SS-56 may present a strong nuclear localization in other cell types or in cells maintained under different growth conditions.

The laboratory diagnosis of autoimmune disorders relies, to a certain extent, on the detection of autoAb's that are associated with a single disease or with a group of diseases. Routine laboratory diagnosis in SS and SLE includes the use of immunofluorescence or ID to evaluate the presence of autoAb's against SSA and SSB antigens (3). Several reports have suggested that these classical techniques are less sensitive than Western blot and ELISA for the detection of anti-SSA-52 antibodies (38-40). Our data confirm these findings and show that among $13 \mathrm{SS}$ and 12 SLE patients who were reported to have no detectable anti-SSA antibodies by ID, six (four SS and two SLE) were found by ELISA to possess measurable antibodies against SSA-52. Among these six patients, two also presented detectable antibodies against SSA-60. On the other hand, the incidence of antibodies to SS-56 was quite elevated in both groups of studied patients. Furthermore, among the

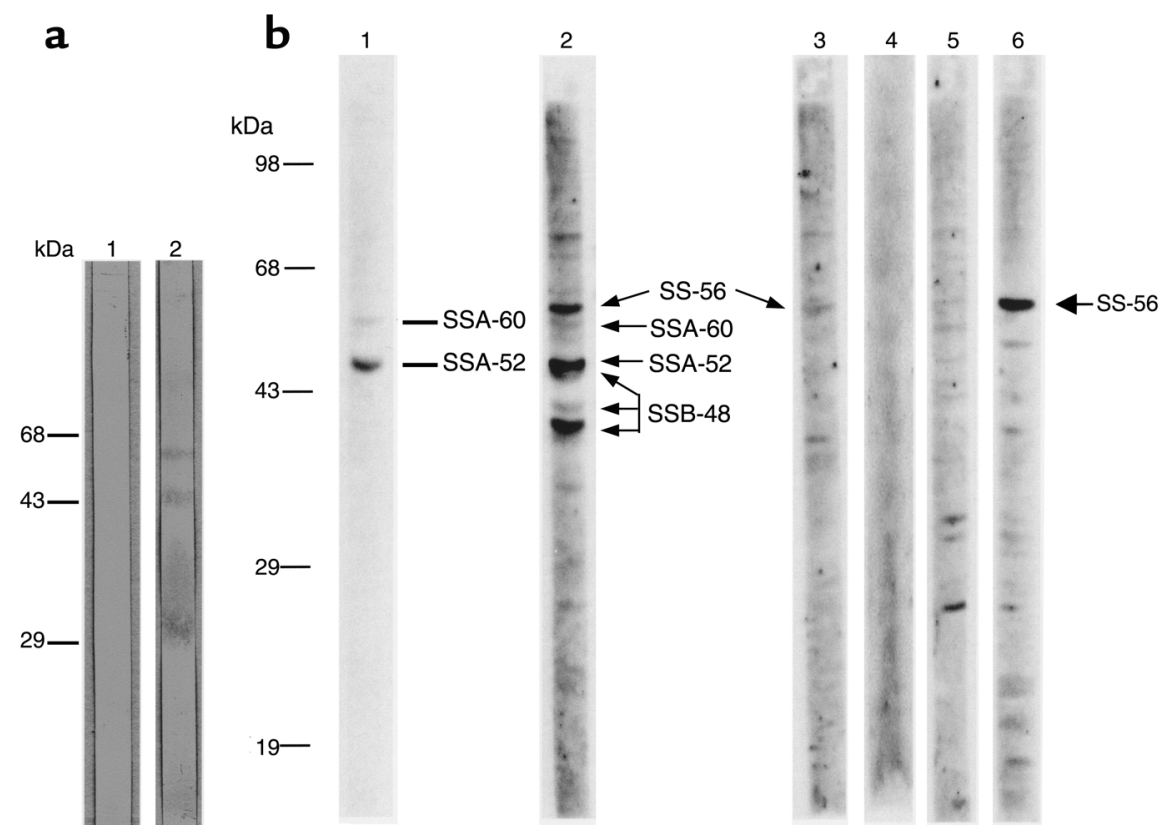

\section{Figure 6}

Reactivity of sera from patients with SS or SLE against His-SS-56 recombinant protein (a) and whole HeLa cell extracts (b), revealed by Western blot. Results are shown for sera from three different patients (lanes 1, 2, and 3) and from one healthy donor (lane 4). The reactivity of preimmune and anti-SS-56 mouse serum are also shown in lanes 5 and 6 , respectively. 


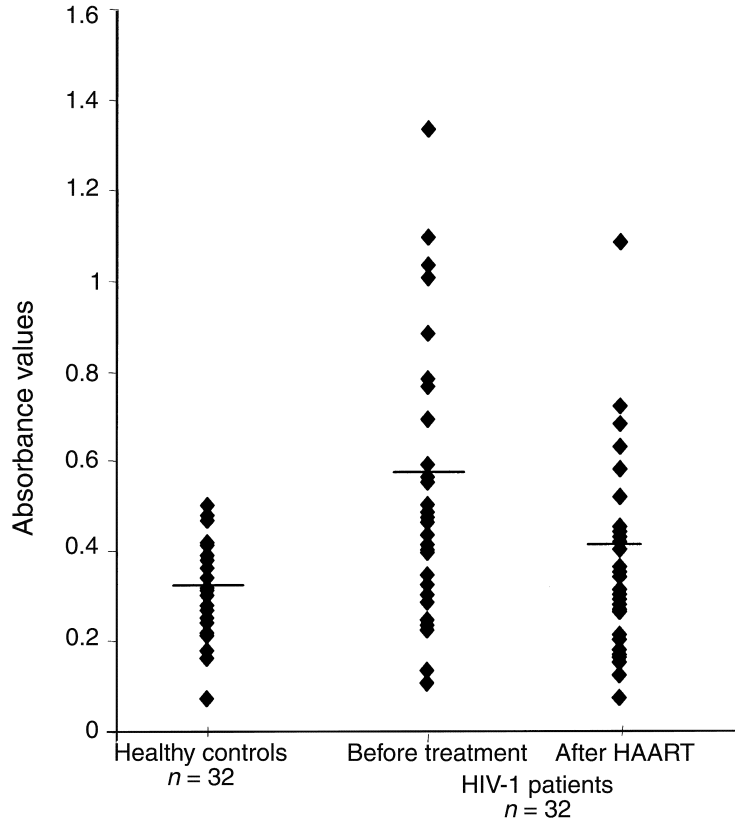

Figure 7

AutoAb's against rSS-56 in sera of HIV- 1 patients tested before and after HAART. Sera from 32 HIV-1 patients, collected at two different time periods before and after HAART, and from 32 healthy controls, were analyzed for autoAb levels to rSS- 56 by ELISA. The presented absorbance values were obtained with a dilution of 1:300, and horizontal bars indicate the means.

25 subjects reported to be negative for SSA and SSB antibodies, 16 presented levels of anti-SS-56 antibodies in ELISA that were above the cut-off point established with values obtained from sera of healthy controls. In addition, among the eight SS and nine SLE patients who were negative against SSA (by ID) and against SSA-52 and SSA-60, by ELISA, four (50\%) and five (56\%), respectively, were found positive for autoAb's against SS-56. These findings establish the newly identified protein SS-56 as an additional cellular target of autoimmune responses in SS and SLE and also argue for the potential use of anti-SS-56 antibodies as a serological diagnostic marker for these two diseases. Nevertheless, it will be important to address in future studies the incidence of anti-SS-56 antibodies in other autoimmune and related connective tissue diseases, to gain further insight into the role of SS-56 in the pathogenesis of autoimmunity. Of particular interest would be studies in NLE, in which antibodies to SS-56, if present, could be correlated with disease pathology. In the same disease, a correlation has been previously reported between the presence of autoAb's to SSA-52 in mothers and the development of NLE and congenital heart block in the newborns $(4,5)$. On the other hand, in patients with either SS or SLE, the presence of autoAb's to SSA or SSB antigen has been associated with a number of clinical manifestations including photosensitivity, sicca syndrome, congenital heart block, and vascular purpura (2). In this study, we could not establish a direct association between the incidence of anti-SS-56 antibodies and either a defined clinical symptom or serum cryoglobulinemia in
SS patients. However, among the SLE patients studied, all those who were negative for autoAb's to SS-56 (seven patients) presented an articular form of the disease without any visceral complication. In contrast, eight of the 15 SLE patients with detectable anti-SS-56 antibodies had a visceral manifestation. These findings establish a link, though in a small cohort, between visceral complications of SLE and autoAb's to SS-56. Larger cohorts would need to be studied in order to validate this association.

AutoAb's against SSA or SSB proteins have been observed in subjects infected with HIV-1 $(7,41)$ but not with hepatitis C (42). On the other hand, sera from SLE and SS patients were also found to present reactivity with HIV-1 p24 antigen (43), suggesting a specific pattern of nonrandom cross-reactivity between virus p24 and autoimmune sera. Moreover, both a direct interaction between the SSB and HIV-1 trans-activation response element as well as the involvement of the SSB autoAg in HIV-1 gene expression have been reported previously (44, 45). Thus, because of the known association between HIV and the SS autoAg and because the identification of SS56 originated from a study on cells from a patient with HIV-1 infection, we evaluated the levels of autoAb's to SS56 in sera of HIV-1 patients. Our findings on the presence of elevated levels of anti-SS-56 antibodies in sera of untreated HIV-seropositive subjects confirm the autoantigenic nature of SS-56 and the autoimmune manifestation of HIV-1 infection (7). Furthermore, the observed normalization in the anti-SS-56 levels after efficacious antiretroviral therapy supports the notion of the ability of antiretrovirals to correct several immune abnormalities (46). The elicitation of autoAb's to various SS antigens, after infection with HIV, may result from a translocation of these proteins to the cell surface of apoptotic cells (47-49), and thereby, these antigens could serve as targets for autoimmune responses. Whether SS-56, similarly to SSA protein, may acquire cell-surface expression upon cell activation or exposure to stress $(50,51)$ would have to be addressed in future studies.

In conclusion, we have cloned the full-length cDNA of a novel autoAg SS-56 that seems to share, besides sequence homology, molecular and physiological characteristics with SSA-52. AutoAb's against SS-56 were detectable in sera of patients with SS or with SLE. Importantly, some patients who showed no reactivity against the classic SSA and SSB antigens were found to present detectable autoAb's to SS-56. Taken together, these findings define a new cellular target of autoimmune responses and point to the potential application of this protein in the diagnosis of SS and SLE. The biologic implications of these results in the pathogenesis of autoimmunity await further studies and a comprehensive profiling of autoAb responses to SS-56 in other autoimmune connective tissue diseases.

\section{Acknowledgments}

This work is supported by a research grant from the Fonds Européens du Développement Régional in France and EKLC is supported by NIH grants AI47859 and AR42455. 
We acknowledge the technical assistance of V. Delsart and S. Coutte and are grateful to S. Dubucquoi for providing the ID diagnostic results for SSA and SSB antibodies.

1. Sibilia, J. 1998. Ro(SS-A) and anti-Ro(SS-A): an update. Rev. Rhum. Engl. Ed. 65:45-57.

2. Bouffard, P., Laniel, M.A., and Boire, G. 1996. Anti-Ro (SSA) antibodies: clinical significance and biological relevance. J. Rheumatol. 23:1838-1841.

3. Mavragani, C.P., Tzioufas, A.G., and Moutsopoulos, H.M. 2000. Sjogren syndrome: autoantibodies to cellular antigens. Clinical and molecular aspects. Int. Arch. Allergy Immunol. 123:46-57.

4. Eftekhari, P., et al. 2001. Induction of neonatal lupus in pups of mice immunized with synthetic peptides derived from amino acid sequences of the serotoninergic 5- HT(4) receptor. Eur. J. Immunol. 31:573-579.

5. Miranda-Carus, M.E., et al. 1998. Induction of antibodies reactive with SSA/Ro-SSB/La and development of congenital heart block in a murine model. J. Immunol. 161:5886-5892.

6. Lee, L.A., Gaither, K.K., Coulter, S.N., Norris, D.A., and Harley,J.B. 1989. Pattern of cutaneous immunoglobulin $\mathrm{G}$ deposition in subacute cutaneous lupus erythematosus is reproduced by infusing purified anti-Ro (SSA) autoantibodies into human skin-grafted mice. J. Clin. Invest. 83:1556-1562.

7. Muller, S., et al. 1992. Autoantibodies typical of non-organ-specific autoimmune diseases in HIV- seropositive patients. AIDS. 6:933-942.

8. Chan, E.K., Hamel, J.C., Buyon, J.P., and Tan, E.M. 1991. Molecular definition and sequence motifs of the $52-\mathrm{kD}$ component of human SSA/Ro autoantigen. J. Clin. Invest. 87:68-76.

9. Ben-Chetrit, E., Gandy, B.J., Tan, E.M., and Sullivan, K.F. 1989. Isolation and characterization of a cDNA clone encoding the $60-\mathrm{kD}$ component of the human SS-A/Ro ribonucleoprotein autoantigen. J. Clin. Invest. 83:1284-1292.

10. Chambers, J.C., and Keene, J.D. 1985. Isolation and analysis of cDNA clones expressing human lupus La antigen. Proc. Natl. Acad. Sci. USA. 82:2115-2119.

11. Keech, C.L., Gordon, T.P., and McCluskey, J. 1995. Cytoplasmic accumulation of the $52 \mathrm{kDa}$ Ro/SS-A nuclear autoantigen in transfected cel lines. J. Autoimmun. 8:699-712.

12. O'Brien, C.A., and Wolin, S.L. 1994. A possible role for the 60-kD Ro autoantigen in a discard pathway for defective $5 \mathrm{~S}$ rRNA precursors. Genes Dev. 8:2891-2903.

13. Pellizzoni, L., Lotti, F., Rutjes, S.A., and Pierandrei-Amaldi, P. 1998. Involvement of the Xenopus laevis Ro60 autoantigen in the alternative interaction of La and CNBP proteins with the 5'UTR of L4 ribosomal protein mRNA. J. Mol. Biol. 281:593-608.

14. Frank, M.B., McCubbin, V.R., and Heldermon, C. 1995. Expression and DNA binding of the human $52 \mathrm{kDa}$ Ro/SSA autoantigen. Biochem. $J$ 305:359-362.

15. Frank, M.B. 1999. Characterization of DNA binding properties and sequence specificity of the human $52 \mathrm{kDa}$ Ro/SS-A (Ro52) zinc finger protein. Biochem. Biophys. Res. Commun. 259:665-670.

16. Maraia, RJ. 1996. Transcription termination factor La is also an initiation factor for RNA polymerase III. Proc. Natl. Acad. Sci. USA. 93:3383-3387.

17. Bachmann, M., et al. 1998. The human autoantigen La/SS-B accelerates herpes simplex virus type 1 replication in transfected mouse 3T3 cells. Clin. Exp. Immunol. 112:482-489.

18. Waysbort, A., Bonnal, S., Audigier, S., Esteve, J.P., and Prats, A.C. 2001 Pyrimidine tract binding protein and La autoantigen interact differently with the $5^{\prime}$ untranslated regions of lentiviruses and oncoretrovirus mRNAs. FEBS Lett. 490:54-58.

19. Meerovitch, K., et al. 1993. La autoantigen enhances and corrects aberrant translation of poliovirus RNA in reticulocyte lysate. J. Virol. 67:3798-3807.

20. Fabini, G., Rutjes, S.A., Zimmermann, C., Pruijn, G.J., and Steiner, G. 2000. Analysis of the molecular composition of Ro ribonucleoprotein complexes. Identification of novel Y RNA-binding proteins. Eur. J. Biochem. 267:2778-2789.

21. Wolin, S.L., and Steitz, J.A. 1984. The Ro small cytoplasmic ribonucleoproteins: identification of the antigenic protein and its binding site on the Ro RNAs. Proc. Natl. Acad. Sci. USA. 81:1996-2000.

22. Wang, D., Buyon, J.P., Zhu, W., and Chan, E.K. 1999. Defining a novel 75-kDa phosphoprotein associated with SS-A/Ro and identification of distinct human autoantibodies. J. Clin. Invest. 104:1265-1275.

23. Bouffard, P., Barbar, E., Briere, F., and Boire, G. 2000. Interaction cloning and characterization of RoBPI, a novel protein binding to human Ro ribonucleoproteins. RNA. 6:66-78.

24. Darcissac, E.C.A., et al. 2000. The synthetic immunomodulator murabutide controls human immunodeficiency virus type 1 replication at multiple levels in macrophages and dendritic cells. J. Virol. 74:7794-7802.

25. Bahr, G.M., et al. 2001. Selective regulation of human immunodeficiency virus (HIV)-infected CD4+ lymphocytes by a synthetic immunomodulator leads to potent virus suppression in vitro and in hu-PBL-SCID mice. J. Virol. 75:6941-6952.

26. Vidal, V.F., et al. 2001. Macrophage stimulation with Murabutide, an
HIV-suppressive muramyl peptide derivative, selectively activates extracellular signal-regulated kinases 1 and 2, C/EBP $\beta$ and STAT1: role of CD14 and Toll-like receptors 2 and 4. Eur. J. Immunol. 31:1962-1971.

27. Altschul, S.F., et al. 1997. Gapped BLAST and PSI-BLAST: a new generation of protein database search programs. Nucleic Acids Res. 25:3389-3402.

28. Vitali, C., et al. 1996. Assessment of the European classification criteria for Sjogren syndrome in a series of clinically defined cases: results of a prospective multicentre study. The European Study Group on Diagnostic Criteria for Sjogren syndrome. Ann. Rheum. Dis. 55:116-121.

29. Billaut-Mulot, O., et al. 2000. Interleukin-18 modulates immune responses induced by HIV-1 Nef DNA prime/protein boost vaccine. Vaccine. 19:95-102.

30. Kozak, M. 1984. Compilation and analysis of sequences upstream from the translational start site in eukaryotic mRNAs. Nucleic Acids Res. 12:857-872.

31. Yoshikawa, T., et al. 2000. Isolation of a cDNA for a novel human RING finger protein gene, RNF18, by the virtual transcribed sequence (VTS) approach(1). Biochem. Biophys. Acta. 1493:349-355.

32. Buyon, J.P., Slade, S.G., Reveille, J.D., Hamel, J.C., and Chan, E.K. 1994. autoantibody responses to the "native" $52-\mathrm{kDa}$ SS-A/Ro protein in neonatal lupus syndromes, systemic lupus erythematosus, and Sjogren syndrome. J. Immunol. 152:3675-3684.

33. Slobbe, R.L., Pluk, W., van Venrooij, W.J., and Pruijn, G.J. 1992. Ro ribonucleoprotein assembly in vitro. Identification of RNA-protein and protein-protein interactions. J. Mol. Biol. 227:361-366.

34. Takahashi, M., Inaguma, Y., Hiai, H., and Hirose, F. 1988. Developmentally regulated expression of a human "finger"-containing gene encoded by the $5^{\prime}$ half of the ret transforming gene. Mol. Cell. Biol. 8:1853-1856.

35. Tissot, C., and Mechti, N. 1995. Molecular cloning of a new interferoninduced factor that represses human immunodeficiency virus type 1 long terminal repeat expression. J. Biol. Chem. 270:14891-14898.

36. Klug, A., and Rhodes, D. 1987. Zinc fingers: a novel protein fold for nucleic acid recognition. Cold Spring Harb. Symp. Quant. Biol. 52:473-482.

37. Schmitz, M., Bachmann, M., Laubinger, J., Thijssen, J.P., and Pruijn, G.J 1997. Characterization of murine monoclonal antibodies against the Ro52 autoantigen. Clin. Exp. Immunol. 110:53-62.

38. Pourmand, N., et al. 2000 . Ro $52 \mathrm{kD}$ autoantibodies are detected in a subset of ANA-negative sera. Scand. J. Rheumatol. 29:116-123.

39. McCauliffe, D.P., Wang, L., Satoh, M., Reeves, W.H., and Small, D. 1997. Recombinant $52 \mathrm{kDa}$ Ro(SSA) ELISA detects autoantibodies in Sjogren syndrome sera that go undetected by conventional serologic assays. $J$. Rheumatol. 24:860-866.

40. Blomberg, S., Ronnblom, L., Wallgren, A.C., Nilsson, B., and KarlssonParra, A. 2000. Anti-SSA/Ro antibody determination by enzyme-linked immunosorbent assay as a supplement to standard immunofluorescence in antinuclear antibody screening. Scand. J. Immunol. 51:612-617.

41. Argov, S., Schattner, A., Burstein, R., Handzel, Z.T., Shoenfeld, Y., and Bentwich, Z. 1991. autoantibodies in male homosexuals and HIV infection. Immunol. Lett. 30:31-35.

42. Verbaan, H., et al. 1999. Extrahepatic manifestations of chronic hepatitis $\mathrm{C}$ infection and the interrelationship between primary Sjogren syndrome and hepatitis C in Swedish patients. J. Intern. Med. 245:127-132.

43. Deas, J.E., et al. 1998. Reactivity of sera from systemic lupus erythematosus and Sjogren syndrome patients with peptides derived from human immunodeficiency virus p24 capsid antigen. Clin. Diagn. Lab. Immunol. 5:181-185.

44. Svitkin, Y.V., Pause, A., and Sonenberg, N. 1994. La autoantigen alleviates translational repression by the $5^{\prime}$ leader sequence of the human immunodeficiency virus type 1 mRNA. J. Virol. 68:7001-7007.

45. Chang, Y.N., Kenan, D.J., Keene, J.D., Gatignol, A., and Jeang, K.T. 1995. Direct interactions between autoantigen La and human immunodeficiency virus leader RNA. J. Virol. 69:618-619.

46. Gray, C.M., et al. 2000. Highly active antiretroviral therapy results in HIV type 1 suppression in lymph nodes, increased pools of naive T cells, decreased pools of activated $\mathrm{T}$ cells, and diminished frequencies of peripheral activated HIV type 1-specific CD8+ T cells. AIDS Res. Hum. Retroviruses. 16:1357-1369.

47. Miranda, M.E., 1998. Accessibility of SSA/Ro and SSB/La antigens to maternal autoantibodies in apoptotic human fetal cardiac myocytes. $J$. Immunol. 161:5061-5069.

48. Miranda-Carus, et al. 2000. Anti-SSA/Ro and anti-SSB/La autoantibodies bind the surface of apoptotic fetal cardiocytes and promote secretion of TNF-alpha by macrophages. J. Immunol. 165:5345-5351.

49. Ayukawa, K., et al. 2000. La autoantigen is cleaved in the COOH terminus and loses the nuclear localization signal during apoptosis. J. Biol. Chem. 275:34465-34470.

50. Igarashi, T., Itoh, Y., Fukunaga, Y., and Yamamoto, M. 1995. Stressinduced cell surface expression and antigenic alteration of the Ro/SSA autoantigen. Autoimmunity. 22:33-42.

51. Dorner, T., et al. 1995. Enhanced membrane expression of the $52 \mathrm{kDa}$ Ro(SS-A) and La(SS-B) antigens by human keratinocytes induced by TNF alpha. Ann. Rheum. Dis. 54:904-909. 